\section{PENGOLAHAN LIMBAH CAIR DI MASJID AGUNG SUMENEP DENGAN SISTEM ECODRAIN}

\author{
Cholilul Chayati ${ }^{1, *)}$. Darma Jasuli ${ }^{2)}$ \\ ${ }^{1}$ Program Studi Teknik Sipil Fakultas \\ Teknik Universitas \\ Wiraraja.cholilul@wiraraja.ac.id \\ ${ }^{2}$ Program Studi Teknik Sipil Fakultas \\ Teknik Universitas \\ Wiraraja.Darmajasuli@wiraraja.ac.id
}

\section{ABSTRAK}

Drainase merupakan sesuatu yang sangat penting karena untuk mengalirkan air yang berlebihan dari permukaan tanah atau dari dalam tanah. Sehingga tidak dapat dipisahkan dari perkembangan suatu daerah. Drainase diperlukan untuk mencegah terjadinya kelebihan air yang dapat menyebabakan terjadinya genangan di suatu daerah atau tempat. Masjid Agung Sumenep salah satu tujuan wisata religi yang menjadi tempat kunjungan wajib bagi wisatawan.dan merupakan masjid Utama yang ada di Sumenep dengan jumlah jamaah 2463 setiap harinya. Di masjid Agung limbah cair langsung di buang ke saluran drainase yang ada.

Volume limbah cair yang di hasilkan oleh jemaah dari kamar mandi dan tempat wudhu sebesar 24.630 liter/orang atau sebesar $24.63 \mathrm{~m}^{3} / \mathrm{hari}$. Desain ecodrain yang direncankan ada 2 tipe. Ecodrain dengan menggunakan sistem anaerob. Aerob dengan 6 tahapan proses pengolahan limbah dan Ecodrain dengan kolam sanitasi dengan 4 tahapan proses pengolah limbah menggunakan tanaman sebagai pengurai limbah

Kata Kunci : drainase, limbah cair, jemaah, ecodrain.

\section{ABSTRACT}

Drainage is very important because it is used to drain excess water from the ground. so that it cannot be separated from the development of an area. Drainage is needed to prevent excess water that can cause puddles in an area or place. The Great Mosque of Sumenep is one of the destinations for religious tourism which is a mandatory visit for tourists. And is the main mosque in Sumenep with 2463 congregations every day. At the Great Mosque. liquid waste is immediately disposed of into the existing drainage channel. no liquid waste treatment has been produced.

The volume of liquid waste produced by the contact person from the bathroom and place of ablution is 24.630 liters / person or $24.63 \mathrm{~m}^{3} /$ day. Ecodrai with a sanitary pond with 4 stages of waste processing process using plants as waste decomposers.

Keywords : drainage, liquid waste, congregation, ecodrain

\section{PENDAHULUAN}

Air adalah suatu kebutuhan pokok yang penting bagi manusia secara berkelanjutan. Sumberdaya air merupakan sumberdaya alam yang dapat diperbaharui (renewable) karena terus menerus dipulihkan melalui siklus hidrologi yang berlangsung menurut hukum alam. Ketersediaan air bersifat terbatas baik pada lingkup ruang dan waktu. Sedangkan kebutuhan air cenderung mengalami peningkatan baik dari segi kuantitas. kualitas. dan jenis kebutuhannya. Drainase merupakan sesuatu yang sangat penting karena untuk mengalirkan air yang berlebihan dari permukaan tanah atau dari dalam tanah.

Masjid Agung Sumenep salah satu tujuan wisata religi yang menjadi tempat kunjungan wajib bagi wisatawan. Dan 
merupakan masjid Utama yang ada di Sumenep dengan jumlah jamaah lebih dari 1000 jamah setiap harinya. Aktifitas keagamaan yang di lakukan oleh jamaah cukup beragam. Salah satunya aktifitas berwudhu dan aktifitas ke kamar mandi. Dan aktifitas tersebut menghasilkan limbah cair. Tentunya dengan jumlah jamaah yang cukup besar maka limbah cair yang di hasilkan cukup besar. Kondisi sekarang di masjid Agung limbah cair langsung di buang ke saluran drainase yang ada. tanpa melalui pengolahan terlebih dahulu. Berdasarakan hal di atas maka pengolahan limbah cair di masjid Agung dianggap penting. Artinya limbah cair yang di hasilkan di Masjid Agung dapat di olah dan di manfaatkan kembali untuk kegiatan non-potable seperti menyiram tanaman, membilas WC. Karena limbah cair dari kamar mandi dan dari air wudhu termasuk limbah Greywater yang bisa di olah dan di maanfaatkan kembali. Pemanfaatan kembali limbah cair dapat membatu meminimalkan penggunaan air tanah yang di pakai untuk penyiraman tanaman di Taman Kota yang letaknya ada di depan masjid Agung sehingga exploitasi pengunaan air tanah dapat di minimalkan serta dapat meminimalkan penggunaan daya listrik untuk memompa air tanah ketika melakukan menyiraman di taman kota.

\section{Tujuan Penelitian}

1. Untuk mengetahui volume limbah cair yang di hasilkan Jamaah

2. Merencanakan pengolahan limbah cair dengan ecodrain.

Menurut UU Nomor 18 Tahun 2008. limbah domestik adalah limbah yang berasal dari kegiatan sehari-hari dalam rumah tangga tetapi tidak termasuk tinja. Kegiatan sehari-hari yang dapat menghasilkan limbah adalah mencuci, memasak, mandi, kegiatan pertanian, kegiatan peternakan.

\section{METODE PENELITIAN}

Lokasi penelitian di Masjid Agung Sumenep

Metode analisa

Metode analisa yang di lakukan adalah:

a. Analisa proyeksi jamaah

Untuk mengatahui berapa jumlah limbah cair yang di hasilkan oleh jamaah selama satu tahun kedepan

b. Karakteristik limbah

Limbah mempunyai ciri-ciri tertentu yang membedakannya dengan benda lainnya. Dibawah ini merupakan beberapa karakteristik limbah diantaranya sebagai berikut:
a. Berukuran Mikro.
b. Bersifat dinamis.
c. Penyebarannya berdampak luas. Berdampak jangka panjang

c. Analisa hidrolika

Untuk menghitung debit jumlah limbah dan untuk mengetahui demensi serta desain kontruksi ecodrain yang cocok di pakai di masjid Agung.

d. Debit Air Kotor

Debit air kotor adalah buangan rumah tangga. instansi. bangunan gedung dan lainnya. Besarnya debit dipengaruhi oleh banyaknya jumlah penduduk dan kebutuhan air penduduk. Dan untuk debit air kotor yang harus dibuang di dalam saluran drainase adalah $70 \%$ dari kebutuhan air bersih. Rumus yang digunakan adalah

$\mathrm{Q}_{\mathrm{ak}}=\frac{\mathrm{P}_{\mathrm{n}} \times \mathrm{q}}{\mathrm{A}}$

e. Kolam Sanitasi

Kriteria yang digunakan untuk merencanakan Kolam Sanitasi:

a) waktu detensi

$\left(t_{d}\right):(1-1.5)$

b) Debit Air Limbah

$\left(Q_{A}\right):(60-80) \%$ x q x n 
Debit Air Limbah Tercampur (60-80) \% x q x n

c) Volume Kolam $=\left(Q_{A}\right) \times\left(t_{d}\right)=P \times L \times T$

\section{HASIL DAN PEMBAHASAN}

\section{Analisa Kandungan limbah Parameter BOD5}

Parameter BOD5 merupakan parameter yang standar beban pencemar organik dalam air. Semakin besar nilai BOD5. Maka semakin tinggi tingkat pencemaran.Kandungan BOD5 limbah cair di Masjid Agung Sumenep sebesar 6.04 $\mathrm{mg} / \mathrm{l}$. Nilainya dibawah baku mutu yaitu 50 $\mathrm{mg} / \mathrm{l}$ dari acuan metode APHA (section 5210 B)-2012. Nilai tersebut menyatakan bahwa limbah cair di Masjid Agung tidak tercemar dan dapat di maanfaatkan kembali.

\section{Analisa Kandungan Parameter COD}

Parameter COD merupkan parameter yang menentukan banyaknya oksigen yang diperlukan untuk mengoksidasi senyawa organik secara kimiawi. Kandungan COD limbah cair di Masjid Agung sumenep sebesar $19.2 \mathrm{mg} / \mathrm{l}$. Berdasarkan SNI 066989.23-2005 tentang Air dan Limbah

\section{Analisa Kandungan Parameter pH}

Untuk proses penjernihannya. Semakin kecil nilai pH-nya. Maka akan menyebabkan air tersebut berupa asam. Air yang normal memiliki $\mathrm{pH}$ sekitar netral. berkisar antara 6 - 9. Hasil dari pengujian laboratorium DLH menunjukan bahwa kandungan $\mathrm{pH}$ limbah cair air sebesar 6.63

\section{Analisa Kandungan Parameter Suhu}

suhu/temperatur limbah cair di Masjid Agung sumenep sebesar $28^{\circ} \mathrm{C}$ berdasarkan SNI 06-6989.23-2005 tentang Air dan Limbah
Analisa Kandungan Parameter TSS

TSS limbah cair di Masjid Agung sumenep sebesar $7.00 \mathrm{mg} / \mathrm{l}$. Berdasarkan pengujian laboratorium DLH tahun 2020

\section{Analisa Kandungan Parameter Minyak Lemak}

Parameter minyak lemak yang bersifat cair. Mempunyai komponen utama karbon dan hidrogen yang mempunyai sifat tidak larut dalam air. Kandungan minyak lemak sebesar $10.3 \mathrm{mg} / \mathrm{l}$ berdasarkan pengujian laboratorium DLH tahun 2020

\section{Data Jumlah Jama'ah Masjid Agung Sumen}

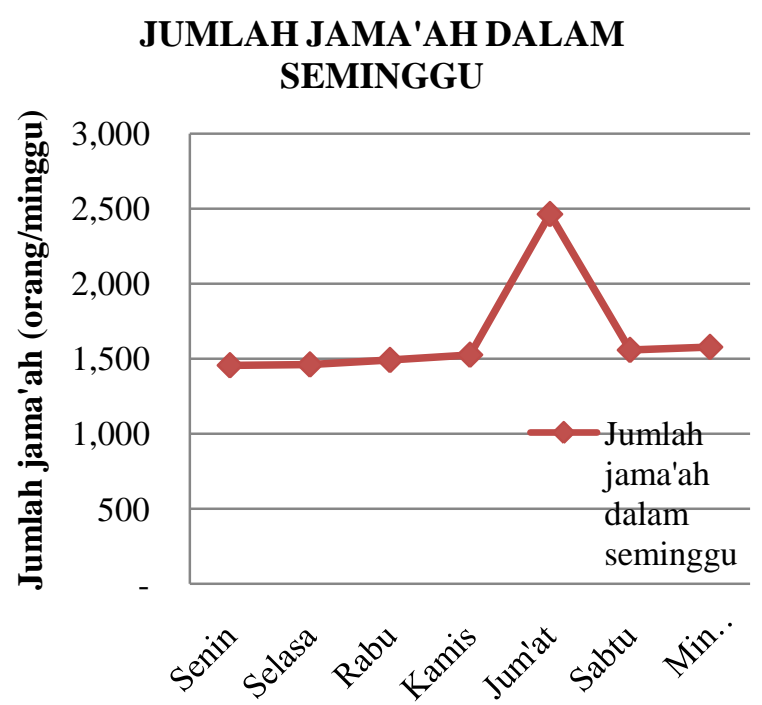

Gambar 1.

Grafik Jumlah Satu Minggu. (Sumber : Analisa Waktu Sholat)

\section{Desain Ecodrain \\ Ecodrain dengan proses Anaerod-aerob}

Jumlah Jama'ah terbanyak Perhari 2.463

Jama'ah

Limbah cair yang dihasilkan 4.926 Liter

Total limbah

Jumlah Jama'ah x Limbah cair /org = 2.463 orang $\mathrm{x} 10$ liter/per orang/hari 24.630 liter/hari. 
Untuk pengolahan limbah cair teknologi yang digunakan adalah kombinasi proses biofilter anaerob-aerob dan dengan sistem kolam sanitasi untuk proses biofilter anaerob-aerob membutuhkan waktu tinggal yang berbeda pada setiap bagian pengolahannya Waktu konsentrasi setiap kompartemen berbeda yaitu :

1. Bak Pemisah Lemak \pm 30 menit.

2. Bak Ekualisasi / Bak Penampungan Air 4-8 jam.

3. Bak pengendapan awal 2-4 jam.

4. Biofilter anaerob 4-8 jam.

5. Biofilter Aerob 4-8 jam.

6. bak pengendapan akhir 2-4 jam. total air limbah yang dihasilkan pada beban puncak harus di tambahkan $30 \%$ untuk memenuhi beban air limbah yang masuk sebelum dan setelah beban puncak.

\section{Kapasitas ecodrain yang Direncanakan}

Total kapasitas bak bengolahan air limbah 32.019 Liter $=32 \mathrm{~m}^{3}$ Perhari

Kapasitas desain yang direncanakan $=32$ $\mathrm{m}^{3} / 24$ jam atau $1.3 \mathrm{~m}^{3} / \mathrm{jam}$

Kapasitas pengolahan permenit $=22$ liter /menit

BOD air limbah rata-rata $6.04 \mathrm{mg} / \mathrm{l}$

Total efisiensi pengolahan $90-95 \%$

\section{Perhitungan Desain}

Bak pemisah lemak atau grease removal di rencanakan dengan tipe gravitasi sederhana. Bak terdiri dari dua kompartemen dengan bar screen pada bagian inletnya. Kapasitas pengolahan 22 liter/ menit. Kriteria perencanaan :

Retention Time $= \pm 30$ menit.

Volume bak yang diperlukan

$\frac{30}{60 \times 24}$ hari $\times 32 \mathrm{~m}^{3} /$ hari

\section{Desain Bak Ekualisasi}

Waktu tinggal didalam Bak $($ HRT $)=4-8$ jam

Ditetapkan : waktu tinggal didalam bak ekualisasi 5 jam.
Volume bak yang diperlukan

Chek : Volume efektif : $8 \mathrm{~m}^{3}$

Waktu tinggal : HRT didalam bak 6 jam

\section{Desain Bak Pengendapan Awal}

Debit air limbah : $32 \mathrm{~m}^{3} /$ hari

$\begin{array}{ll}\text { BOD masuk } & : 6.04 \mathrm{mg} / \mathrm{l} \\ \text { Efisiensi } & : 25 \% \\ \text { BOD }_{\text {keluar }} & : 4.53 \mathrm{mg} / \mathrm{l}\end{array}$

Waktu tinggal didalam bak $=2-4$ jam Volume bak yang diperlukan $=\frac{3}{24}$ hari $\mathrm{x}$ $32 \mathrm{~m}^{3} /$ hari

Chek :Waktu tinggal

(Retention Time) rata-rata(T) 3 jam

Beban permukaan (surface loading) 16 $\mathrm{m}^{3} / \mathrm{m}^{2}$.hari

Waktu tinggal pada saat beban puncak = 1.5 jam

Beban permukaan (surface loading) ratarata $=16 \mathrm{~m}^{3} / \mathrm{m}^{2}$.hari

Beban permukaan pada saat puncak $=20$ $\mathrm{m}^{3} / \mathrm{m}^{2}$.hari

Standar : waktu tinggal $=2-4$ jam

Beban permukaan $=20-50 \mathrm{~m}^{3} / \mathrm{m}^{2}$.hari (JWWA)

\section{Biofilter Anaerob}

Debit air limbah : $32 \mathrm{~m}^{3} /$ hari

$\begin{array}{ll}\text { BOD masuk } & : 4.53 \mathrm{mg} / 1 \\ \text { Efisiensi } & : 80 \% \\ \text { BOD }_{\text {keluar }} & : 0.91 \mathrm{mg} / \mathrm{l}\end{array}$

Ditetapkan beban BOD yang digunakan = $0.4 \mathrm{~kg} \mathrm{BOD} / \mathrm{m}^{3}$.hari

Beban BOD didalam air limbah $=0.145$ $\mathrm{kg} / \mathrm{hari}$

Volume media yang diperlukan $=0.362 \mathrm{~m}^{3}$

Volume media $=60 \%$ dari total volume reaktor.

Voume reaktor yang diperlukan $=0.60 \mathrm{~m}^{3}$

Waktu tinggal didalam reaktor anaerob $=$ $\frac{0.60 \mathrm{~m}^{3}}{32 \mathrm{~m}^{3} / \mathrm{hari}} \times 24 \mathrm{jam} / \mathrm{hari}$

Jumlah ruang $\quad: 2$ ruang

Waktu tinggal reaktor anaerob rata-rata $=$ $0.45 \mathrm{jam} / 45$ menit

Waktu tinggal rata-rata: 0.45 jam

Tinggi ruang lumpur $: 0.2 \mathrm{~m}$ 
Tinggi bed media pembiakan mikroba : 0.5 $\mathrm{m}$

Tinggi air diatas bed media : $30 \mathrm{~cm}$

Volume media pada biofilter anaerob: $1 \mathrm{~m}^{3}$

\section{Biofilter Aerob}

$\begin{array}{ll}\text { Debit air limbah }: 32 \mathrm{~m}^{3} / \text { hari } \\ \text { BOD masuk } & : 0.91 \mathrm{mg} / 1 \\ \text { Efisiensi } & : 60 \% \\ \text { BOD }_{\text {keluar }} & : 0.36 \mathrm{mg} / 1\end{array}$

Beban BOD didalam air limbah : 0.029 $\mathrm{kg} / \mathrm{hari}$

Jumlah BOD yang dihilangkan : 0.017 $\mathrm{kg} / \mathrm{hari}$

Beban BOD per volume media yang digunakan $\quad: 0.4 \mathrm{~kg} / \mathrm{m}^{3}$.hari

Volume media yang diperlukan : $0.072 \mathrm{~m}^{3}$

Volume reaktor biofilter aerob yang diperlukan $: 8 \mathrm{~m}^{3}$

Biofilter aerob di rencanakan dua kompartemen yaitu ruang aerasi dan ruang bed media.

Chek :

1. Waktu tinggal total rata-rata $=6$ jam

2. Waktu tinggal total pada saat beban puncak : 2 jam

3. Tinggi ruang lumpur: $0.5 \mathrm{~m}$

4. Tinggi bed media pembiakan mikroba : $1 \mathrm{~m}$

5. Volume total media pada biofilter aerob $=2 \mathrm{~m} \times 2 \mathrm{~m} \times 1.5 \mathrm{~m}^{3}$

Chek :

BOD loading per volume media $=(0.029 /$

6) $\mathrm{BOD} / \mathrm{m}^{2}$.hari

Standar high rate trickling filter : $0.4-4.7$ $\mathrm{kg} \mathrm{BOD} / \mathrm{m}^{2}$.hari

Kebutuhan Oksigen :

Jumlah BOD yang dihilangkan $0.017 \mathrm{~kg} / \mathrm{hari}$.

Faktor keamanan ditetapkan \pm 2.0

Kebutuhan oksigen teoritis $0.034 \mathrm{~kg} / \mathrm{hari}$.

Temperature udara rata-rata $=28{ }^{\circ} \mathrm{C}$

Berat udara pada suhu $28{ }^{\circ} \mathrm{C} 32 \mathrm{~kg} / \mathrm{m}^{3}$

Diasumsikan jumlah oksigen didalam udara $20 \%$. Jadi Jumlah kebutuhan udara teoritis $0.005 \mathrm{~m}^{3} /$ hari.

Efisiensi diffuser $3 \%$
Kebutuhan udara aktual $=0.1 \mathrm{~m}^{3} /$ hari Atau 100 liter/menit

Blower Udara Yang diperlukan :

Spesifikasi Blower :

Tipe

: HIBLOW 200

Kapasitas Blower

Head

: 200 liter/menit

Jumlah

: 2 meter

Power

Pipa outlet

: 4 unit

Kelistrikan

: 800 watt

$: 1 / 2$ Inc.

$: 1$ fase

Difuser udara: $=800$ liter/menit

\section{Desain Bak Pengendap Akhir}

Debit air limbah : $32 \mathrm{~m}^{3} /$ hari

BOD masuk $\quad: 0.36 \mathrm{mg} / \mathrm{l}$

BOD $_{\text {keluar }} \quad: 0.36 \mathrm{mg} / \mathrm{l}$

Waktu tinggal didalam bak $2-4$ jam

Volume bak yang diperlukan $4 \mathrm{~m}^{3}$

Chek :

Retention Time rata-rata(T) 3 jam

surface loading $16 \mathrm{~m}^{3} / \mathrm{m}^{2}$.hari

Waktu tinggal saat beban puncak $1.5 \mathrm{jam}$ surface loading rata-rata $16 \mathrm{~m}^{3} / \mathrm{m}^{2}$.hari

Beban permukaan pada saat puncak 20 $\mathrm{m}^{3} / \mathrm{m}^{2}$.hari

Standar: waktu tinggal $2-4$ jam

Beban permukaan $20-50 \mathrm{~m}^{3} / \mathrm{m}^{2}$, hari (JWWA).

\section{Q air limbah setelah di olah}

Debit air limbah $=24.63 \mathrm{~m}^{3} /$ hari $=1.026$

$\mathrm{m}^{3} / \mathrm{jam}=17.10$ liter $/$ menit

\section{Kolam Sanitasi}

Kriteria yang digunakan untuk merencanakan Kolam Sanitasi:

Waktu detensi

$\left(\mathrm{t}_{\mathrm{d}}\right) \quad:(1-1.5)$ hari. diambil 1 hari

Debit Air Limbah $\left(\mathrm{Q}_{\mathrm{A}}\right):(60-80) \% \mathrm{xqxn}$

Pemakaian air : 10 1/orang/hari

Jumlah pemakai (n) : 2.463 orang

Perhitungan:

1. Debit Air Limbah Tercampur

$(60-80) \%$ x q x n

19.704 1/hari $=19.704 \mathrm{~m}^{3}$

2. Volume Kolam $=\left(\mathrm{Q}_{\mathrm{A}}\right) \times\left(\mathrm{t}_{\mathrm{d}}\right)$

$=19.704 \mathrm{~m}^{3}$ 


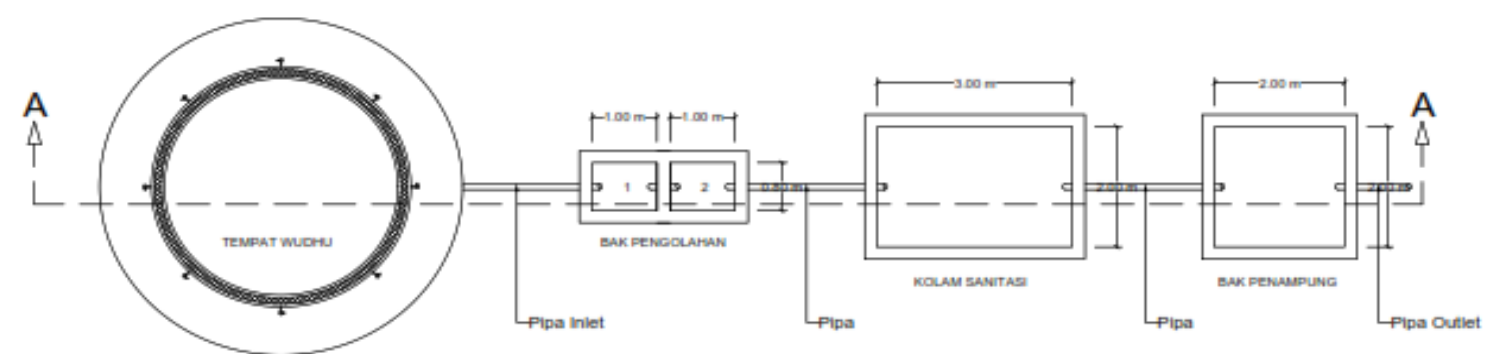

Gambar 2.

Desain Ecodrain dengan Kolam Sanitasi

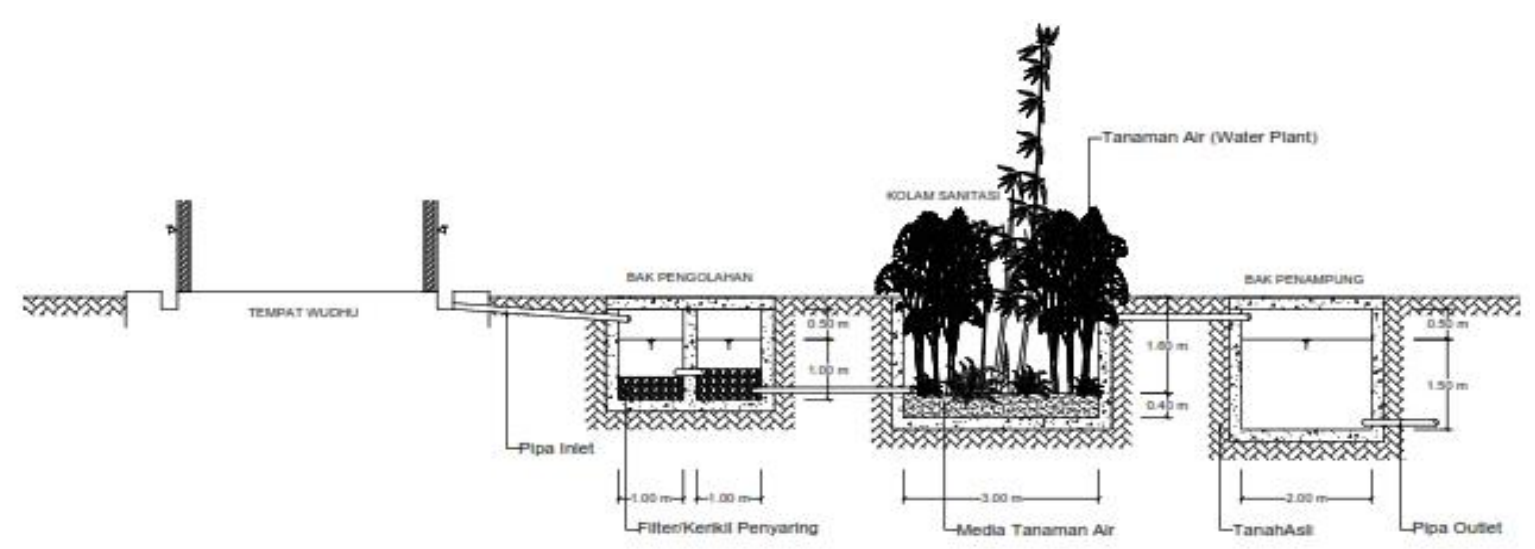

Gambar 3.

Potongan A-A Ecodrain dengan Kolam Sanitasi

\section{KESIMPULAN}

Berdasarkan hasil analisa di atas dapat di terik kesimpulan yaitu

1. Debit limbah cair yang di hasilkan oleh jamah sebesar $24.63 \mathrm{~m}^{3} /$ hari

2. Desain ecodrain yang direncankan ada 2 jenis desain ecodrain sistem anaerob dan aerob dengan 6 tahapan proses pengolahan limbah
a. Ecodrain dengan menggunakan
b. Ecodrai dengan kolam sanitasi dengan 4 tahapan proses pengolah limbah menggunakan tanaman sebagai pengurai limbah

\section{DAFTAR PUSTAKA}

Arsyad. Muh., (2016), Jurnal Teknik Sipil Perencanaan Sistim Perpipaan Air Limbah Kawasan Pemukiman Penduduk.
Binilang. Alex. Fuad. Halim. Mubin. Fathul., (2016), Jurnal Sipil Statik. Perencanaan Sistem Pengolahan Air Limbah Domestik Di Kelurahan Istiqlal Kota Manado.

Saptomo. Satyanto Krido. Setjo1. Budiaji Teguh. Wirasembada. Yanuar Chandra., (2016), Perencanaan Tangki Septik Komunal Di Desa Suwaru. Kecamatan Pagelaran. Kabupaten Malang. Jawa timur.

SNI 06-6989.23., (2005), Air dan limbah cara.

SNI 2398.,(2017), Tata cara perencanaan tangki septik dengan pengolahan lanjutan (sumur resapan. bidang resapan. up flow filter. kolam sanita).

Sugiarto.,(2008), Dasar-dasar Pengolahan Air Limbah. Universitas Indonesia. Jakarta 